\title{
Geriatrik Hastalarda Unutkanlık mı? Demans mı?: Bir Olgu Nedeni ile
}

\author{
Is this Forgetfulness in the Elderly Patients? Is this Dementia in the Elderly \\ Patients?: A Case Report
}

\section{Özet}

Unutkanlık ve hafıza fonksiyonlarında azalma, yaşlılarda oldukça sık görülen yakınmalardır. Hastaneye yatıılan geriatrik bireylerde ortam değişikliğine bağlı ortaya çıkabilecek böyle uyumsuzlukları vurgulamak ve bu hastaların ayrıntılı değerlendirilmeden demans denilmemesine dikkat çekmek adına bu vakayı sunduk. (Türk Osteoporoz Dergisi 2013;19: 56-7)

Anahtar kelimeler: Yaşlıık, unutkanlık, demans

\section{Summary}

Forgetfulness and reduction of memory function in the elderly is common complaints. We have presented this circumstance because of taking attention to say demans without a detailed evaluation of these patients and to express the inconsistency on the medium exchanges on the hospitalized geriatric. (Turkish Journal of Osteoporosis 2013;19: 56-7)

Key words: Old age, forgetfulness, dementia

\section{Giriş}

Tüm dünyada yaş ortalamasının giderek artmasıyla geriatrik hastaların değerlendirilmesi ve bakımı önem kazanmaktadır. Yaşı bir hastanın doğru tanı ve tedavi alması, hayat kalitesinin arttıııması ve fonksiyonel bağımsızlı̆̆ını sürdürmesi için kapsamlı geriatrik değerlendirme şarttır (1). Unutkanlık ve hafıza fonksiyonlarında azalma, yaşlılarda oldukça sık görülen yakınmalardır. Toplum temelli çalısmalarda, yaşlılardaki hafıza ile ilgili yakınmaların prevalansının \%25-50 arasında olduğu saptanmıştır (2). Demans bellek başta olmak üzere pek çok bilişsel işlevde ilerleyici bozulma ile karakterize mesleki ve toplumsal işlevsellikte bozulmaya yol açan ve yıkımla sonlanan bir hastalıktır. Altmış beş yaş ve üzeri kişilerde demans görülme sıklı̆ı \%10-15, 80 yaş ve üzerinde ise \%40-50'dir (3-5)

\section{Olgu}

Yetmiş yedi yaşında bayan hasta diz osteoartriti tanısıyla fizik tedavi programı almak üzere kliniğimize yatııılı. Özgeçmişinde hipertansiyonu vardı. Soygeçmişinde herhangi bir özellik yoktu. Hastanın tedavi sırasında yattığı odayı bulmakta güçlük çektiği, yanlış odalara yöneldiği ve bundan dolayı programını aksattığı gözlendi. Demans açısından değerlendirilen hastanın mini mental testi (MMT) 25 olarak bulundu. Nöropsikiyatrik değerlendirilme sonucunda hastada demans olmadığına ve yaşlıı̆̆a bağlı unutkanlık olduğuna karar verildi. Sonuçta, çözüm olarak hastanın odasının kapısına bir işaret koyulup odasının diğer odalardan ayrılarak, hastanın fizik tedavi programına uyum sağlaması arttıııdı.

\section{Tartışma}

Unutkanlığın, kognitif ve fonksiyonel yetersizliklerin yaşlılığın doğal bir sonucu olduğu yanlış inanışının gerek toplumda gerekse hekimlerde yaygın olması yıllardır yaşlıda demans tanısının az olmasına sebep olmaktadır (6). Öte yandan unutkanlığı olan tüm geriatrik bireylere de demans tanısı koymak kolay fakat bireyi etiketleyen bir durumdur. Yapılan bir araştırmada 3954 birinci basamak hastası değerlendirilmiş, altmış yaş ve üzeri hastaların $\% 10,5^{\prime}$ i minimal kognitif bozukluk, \%5,2'si orta-ileri demans tanı kriterlerini karşılamalarına rağmen minimal kognitif bozukluk hastalarının \%3,2'üne, orta-ileri demans hastalarının ise \%23'üne doğru tanı konulabildiği görülmüştür (7). Bu nedenle de hekim 
için yaşlı bireydeki unutkanlığın normal yaşlanma sürecine mi bağlı olduğu, yoksa demansın öncü belirtisi mi olduğuna karar vermek oldukça zordur (2). Çünkü genç insanlarla karşılaştııldığında yaşlı bireylerin, zamana dayalı kognitif fonksiyon değerlendirmelerinde işlem ve reaksiyon hızları daha yavaş olmaktadır. Bu durum yaşlanmanın getirdiği hafif dereceli bir bozukluk ise, kişi geç de olsa o bilgiyi hatırlar. Öğrenme yetisi intakttır. Hafızayla ilgili bu yavaşlama ilerleyici değildir, zamanla artma eğilimi göstermez. Bir unutkanlığın demans sendromuna ait bir bulgu olabilmesi için, kognitif alanlardan (öğrenme, bellek, oryantasyon, dil fonksiyonları ve kişilik) en az birindeki bozulmanın unutkanlığa eşlik etmesi gerekmektedir. Hafif kognitif bozukluk normal unutkanlık ve demans arasındaki bir tablodur. Önce yakın bellek bozulmakta, birey kelime bulma ve akıcı bir konuşmayı sürdürmede güçlük çekmektedir, daima aynı soruları sorma eğilimindedirler. İyi eğitimli hastalar erken evrede eksikliklerini kompanze edebilirler, ayrıntılı öykü alındığında karmaşık günlük aktiviteleri (maaş takibi, fatura yatırma, alışveriş ve hesap yapma vs) yürütmede zorlandıkları gözlenmektedir. Daha sonraki dönemlerde bilişsel kayıplar ortaya çıkmaktadır. Uzak bellek bozulmaya başlayıp, gündemi ve ailedeki olayları takip edememeye başlamaktadırlar. Önce evini, sonra evinde odaları bulamamaya başlamaktadır, kendine bakımı giderek bozulmaktadır. Bizim olgumuzda da yattığı odayı bulamama şikayeti vardı. Sorguladığımızda evini ve evindeki odaları bulmakta güçlük çekmediği, unutkanlığının progresif olmadığı öğrenildi. Kognitif fonksiyonların değerlendirilmesinde sıkça kullanılan MMT'in 24 puanın altında olması demansı, 24-26 puan arası hafif kognitif bozukluğu, 26 puan ve üzeri ise normal kognitif fonksiyonları göstermektedir $(6,8)$. Olgumuzun MMT'nin 25 olması kognitif fonksiyonların hafif bozulduğunu göstermektedir. Olgumuzda olduğu gibi geriatrik hastalarda ortam değişikliği hastaların adaptasyonunu bozmaktadır ve unutkanlık ya da silik kognitif bozukluklar daha belirginleşmektedir. Bu durumda da hastaların tedaviye uyumu azalmaktadır. Özellikle böyle hastaların ilaç kullanımına dikkat edilmeli, bu konuda hemşiresi uyarılmalıdır. Yine uyum sürecinde yabancı ortamdan kaynaklanan düşmeleri önlemek için yardımcı cihaz kullanımı önerilip yardımcı sağlık personelinin hastaya çevresel ortamı tanıtıcı tekrarlayan desteklerde bulunması sağlanılabilir. Çünkü düşmelerde kognitif bozukluğun önemli bir risk faktörü olduğu daha önce yapılan çalışmalarda gösterilmiştir (9). Tanısı konmuş demans hastaların tedavilerinde en az ilaçlar kadar aktivite planları, mekânsal düzenlemeler ve bakım verenlerin eğitiminin çok önemli olduğu vurgulanmıştır (10) .

Hastaneye yatıılan geriatrik bireylerde ortam değişikliğine bağlı ortaya çıkabilecek böyle uyumsuzluklardan dolayı gerekli önlemler alınmalı, hospitalize edilen geriatrik hastalar ayrıntılı değerlendirilmeden demans denilmemelidir. Özetle böyle klinik deneyimlerle, geriatrik rehabilitasyonda hastanın her açıdan dikkatli değerlendirilmesinin tedavi başarısındaki önemi belirginleşmektedir.

\section{Kaynaklar}

1. Rosenthal RA, Kavic SM. Assessment and management of the geriatric patient. Crit Care Med 2004;3:92-105.

2. Işık AT. Unutkanlığı Olan Yașlıya Yaklaşım. Journal Geriatrics and Geriatric Neuropsychiatry 2009;1:33-8.

3. Terry RD, Katzman R, Bick KL, Sisodia SS. Alzheimer hastalığı. In: Hakan Gürvit, editör. İstanbul: Yelkovan yayıncılık; 2001.

4. Karaman Y. Alzheimer hastalığı ve Diğer Demanslar. 1st ed. Ankara: Lebib Yalkın Matbaası; 2002.

5. Souder E, Beck C. Overview of Alzheimer's disease. Nurs Clin North Am 2004;39:545-59.

6. Petersen RC, Doody R, Kurz A, Mohs RC, Morris JC, Rabins PV, et al. Current concepts in mild cognitive impairment. Arch Neurol 2001;58:1915.

7. Callahan CM, Hendrie HC, Tierney WM. Documentation and evaluation of cognitive impairment in elderly primary care patients. Ann Intern Med. 1995;122:422-9.

8. Petersen RC, Stevens JC, Ganguli M, Tangalos EG, Cummings JL, DeKosky ST. Practice parameter: Early detection of dementia: Mild cognitive impairment (an evidence-based review). Report of the Quality Standards Subcommittee of the American Academy of Neurology. Neurology 2001;56:1133.

9. Scheffer AC, Schuurmans MJ, Van Dijk N, van der Hooft T, de Rooji SE. Fear of falling measurement, strategy, prevalance risk factors an consequences among older persons. Age Ageing 2008:37:19-24.

10. Yalçın M, Ertan T. Deliryum ve demans: Genel özellikler ve ayırıı tanı. Görüntüleme Yöntemleri Sempozyum Dizisi 2010;69:9-31. 